\title{
FINANCIAMIENTO Y DISTRIBUCIÓN DEL GASTO EN LA CAJA REAL DE MALDONADO (RÍO DE LA PLATA), 1782-1806
}

\author{
FUNDING AND ALLOCATING EXPENDITURE \\ IN THE CAJA REAL OF MALDONADO \\ (RIO DE LA PLATA), 1782-1806
}

\author{
Nicolás Biangardi \\ Universidad Nacional de La Plata, La Plata, Argentina, \\ nicolas_biangardi@yahoo.com.ar
}

\begin{abstract}
Resumen. Este artículo analiza el gasto fiscal realizado por la Real Hacienda en el área de Maldonado. A partir del análisis de los datos contenidos en los libros contables de la Caja Real de Maldonado se estudian las erogaciones de caudales efectuadas en el periodo comprendido entre 1782 y 1806 , que estaban orientadas a solventar la política de poblamiento de la zona y la defensa militar del territorio. El trabajo también muestra que ese gasto fiscal fue sostenido, en su mayor parte, por las transferencias provenientes de las cajas de Buenos Aires y Montevideo, que a su vez recibían esos fondos de otras cajas. De esta manera durante 25 años se produjo una inyección constante de moneda metálica en Maldonado que, en última instancia, procedía de los excedentes de las cajas mineras del Alto Perú y que ayudó a consolidar el crecimiento demográfico y económico de la zona.
\end{abstract}

Palabras clave: gasto fiscal; Real Hacienda; poblamiento; defensa militar; Maldonado.

Abstract. This paper analyses the fiscal expenditure of the Real Hacienda (Royal Treasury) in the area of Maldonado. The expenditure of wealth from 1782 to1806, oriented to fund the settlement policy in that region and the military defence of the land, was studied through the analysis of data from accounting books of the Caja Real (Royal Cash Office) of Maldonado. This paper also shows that fiscal expenditure was mostly sustained by transfers from the cash offices of Buenos Aires and Montevideo that, in turn, received funds from other cash offices. Thus, coins were constantly injected, ultimately, from mining surplus in the cash office of Upper Peru into Maldonado for 25 years. This injection of coins helped consolidate the demographic and economic growth of the region.

Key words: fiscal expenditure; Real Hacienda; settlement; military defence; Maldonado.

Fecha de recepción: 14 de octubre de 2014. Fecha de aceptación: 6 de mayo de 2015.

Am. Lat. Hist. Econ., mayo-agosto, 2016, pp. 7-35 | DOI: 10.18232/alhe.v23i2.707 


\section{INTRODUCCIÓN}

$\mathrm{L}$ a segunda mitad del siglo XVIII fue testigo de profundos cambios en la monarquía borbónica. Varias de esas transformaciones tuvieron su origen en la necesidad de defender los dominios americanos de la corona. La guerra de los Siete Años (1756-1763) había demostrado la necesidad de reforzar militarmente ese territorio, en especial algunos lugares estratégicos. Dentro de ese contexto, los funcionarios borbónicos que desempeñaban sus funciones en el Río de la Plata emprendieron una política que incluía la construcción y mantenimiento de fortificaciones y el poblamiento de zonas fronterizas.

Las distintas actividades que implicaban el asentamiento de pobladores, el mantenimiento de destacamentos y fortificaciones militares generaban una demanda constante de bienes y un importante gasto salarial. La recaudación de impuestos por parte de la Real Hacienda en el Río de la Plata no podía hacer frente a este nivel de gastos. En consecuencia, los caudales necesarios para sostener la política de defensa debían ser financiados con los excedentes de las tesorerías ubicadas en las zonas mineras del Alto Perú. Sin embargo, esto no era una particularidad del Río de la Plata. Esas transferencias de dinero con objetivos militares eran una práctica habitual de la Real Hacienda, tal como lo muestra el trabajo de Marichal y Souto (2012) respecto a que la defensa del Caribe español se sostenía con la plata enviada desde Nueva España, y los de Meisel (2000) y Muñoz (2010) en relación con el financiamiento de Cartagena de Indias dentro del virreinato de Nueva Granda, y el de Flores (2012) para el caso de los situados que Panamá y Chile recibían desde Lima.

Los estudios sobre el gasto fiscal de la monarquía borbónica han destacado el lugar predominante del sector militar en las asignaciones presupuestarias (Barbier y Klein, 1985). Recientemente se plantea, incluso, la posibilidad de caracterizar a la corona española como un Estado fiscal militar para mostrar, de esa manera, la centralidad que el gasto militar tuvo en la configuración de toda la estructura burocrática (Torres-Sánchez, 2007, 2013). Aunque esos trabajos basados en las fuentes de la Tesorería General de Madrid sólo tienen en cuenta los gastos militares que la monarquía efectuaba en Europa, dejando de lado las inmensas erogaciones que la Real Hacienda realizaba para la defensa de todo el territorio hispanoamericano y que originaban las transferencias entre cajas a las que hacíamos mención.

Por otra parte, las investigaciones sobre fiscalidad para el Río de la Plata durante el periodo también han destacado la importancia del gasto militar. Halperín (1982) analizó los ingresos y egresos de la Real Caja de Buenos Aires a partir de 1791. Señala que la mayor parte de los ingresos 
provenían de otras tesorerías y que los sueldos representaban la mayor parte de los gastos. Además, considera que luego de los salarios los mayores gastos eran los destinados a la defensa de la amplia frontera terrestre y marítima, y que esa transferencia de fondos impactó especialmente en la Banda Oriental (Halperín, 1982, p. 43). Sin embargo, ese impacto no forma parte de su análisis ya que el objetivo del autor era conseguir un marco de referencia para entender las transformaciones fiscales del posterior proceso de formación del Estado argentino y por ende su objeto de estudio se restringió a Buenos Aires.

Por su parte, Herbert Klein (1999) presentó los datos de ingresos y egresos de las cajas rioplatenses para todo el siglo XVIII. El autor destaca la insuficiencia de la recaudación de ingresos del Río de la Plata debida a los costos de la defensa local y su dependencia de los excedentes de las cajas del Alto Perú. En cambio, Martín Cuesta (2009), luego de un análisis de los libros de la Caja Real de Buenos Aires a lo largo de todo el siglo XVIII, considera que la recaudación fiscal era suficiente para cubrir los gastos locales. Esto se debe a que, como en el caso de Halperín Donghi, reduce su objeto de estudio a Buenos Aires y por lo tanto no considera el gasto militar de la frontera imperial como gasto local.

Por otro lado, Samuel Amaral (2011) indaga sobre los mecanismos a los que recurrió la Caja Real de Buenos Aires para enfrentar el déficit fiscal entre 1789 y 1811. Principalmente la Real Hacienda recurría a la transferencia de fondos entre ramos que luego devolvía con la llegada de los caudales provenientes de otras tesorerías. En el sistema contable de partida simple esas operaciones tienden a aumentar de manera ficticia tanto el cargo como la data, lo que nos obliga a tener recaudos, desconfiar de las cuentas anuales y a revisar los libros en su totalidad. ${ }^{1}$

Finalmente, Fernando Jumar y María Emilia Sandrín (2013) estudian de qué manera ese gasto fiscal podía dinamizar la economía de la región a partir de un análisis de la Caja Real de Buenos Aires entre 1734 y 1742 y las cuentas del sitio a Colonia de Sacramento de los años 1735-1737. Su trabajo muestra que la economía minera del Alto Perú financiaba el crecimiento económico del Río de la Plata por medio de los caudales invertidos por parte de la Real Hacienda.

${ }^{1}$ Amaral (1984) criticó el uso de las cuentas anuales denominadas cartas cuenta por parte de Klein (1973) y mostró las diferencias sustanciales que se presentan al descontar las transferencias entre ramos. En Amaral (2011) se puede observar que esas prácticas fueron habituales y que implicaron cantidades significativas de los dineros manejados por la Caja Real de Buenos Aires. Por su parte, Ernest Sánchez Santiró (2013) ha insistido nuevamente en la necesidad de contrastar las cartas cuenta con la información contenida en los libros de caja en su análisis sobre la Real Hacienda de Nueva España en el periodo 1744-1748. 
Siguiendo esta línea de análisis, en este trabajo se estudiaron los libros de la Caja Real de Maldonado. El área de Maldonado se encontraba situada en la orilla norte del Río de la Plata, entre el límite este de la jurisdicción de Montevideo y la costa del océano Atlántico, y se extendía hacia el norte hasta encontrar las tierras dominadas por los portugueses al sur de Río Grande. ${ }^{2}$ Considero que el caso de Maldonado representa una oportunidad única para analizar la relación entre gasto fiscal y crecimiento económico. Ocupada recién en la segunda mitad del siglo XVIII, la zona se benefició con la política de poblamiento de la corona. Al mismo tiempo, su posición estratégica, que aunaba la desembocadura del estuario, una amplia franja costera sobre el Atlántico y la frontera con los dominios lusitanos, determinaba una importante transferencia de caudales hacia el lugar.

En un trabajo previo analicé la relación entre el gasto fiscal, el crecimiento demográfico y el desempeño de la economía agropecuaria del área en esos años (Biangardi, 2013a); en esta ocasión, se estudian con detenimiento los ingresos y egresos de la Caja Real de Maldonado para establecer el origen de los fondos y las dimensiones de los gastos que ocasionaron tanto la política de poblamiento como la defensa del territorio en la zona. ${ }^{3}$

\section{La Real Hacienda en Maldonado}

Las cuentas de la Real Hacienda en Maldonado comenzaron en 1778 con la llegada de Rafael Pérez del Puerto, quien había sido designado como interventor y pagador de las Reales Obras de Fortificación del lugar. ${ }^{4}$ Sin embargo, los libros de la Caja Real de Maldonado comienzan recién en 1782 y se extienden hasta que la invasión inglesa a esta área en 1806 interrumpiera el accionar de la institución.

La creación de la caja se dio entonces en el contexto de la expansión del aparato burocrático en el Río de la Plata que se produjo como consecuencia del establecimiento del nuevo virreinato. En tanto que uno de los objetivos era consolidar definitivamente el dominio de la corona sobre

${ }^{2}$ Uso el término área porque considero que el espacio geográfico al que me refiero forma parte de un espacio más amplio denominado región Río de la Plata. Para una definición de la región Río de la Plata, véanse Jumar (2012) y Jumar y Biangardi (2014), y para una delimitación del área de Maldonado, véase Biangardi (2013a y 2013b).

${ }^{3}$ Se considerarán solamente los aspectos económicos de la política de poblamiento. Julio Djenderedjian (2008) ha señalado la importancia de los recursos institucionales que brindaba esa política para la conformación de nuevos espacios de poder local que tuvieron un desempeño preponderante en los sucesos políticos a principios del siglo XIX.

${ }^{4}$ Vida y obra de este funcionario, que fue el encargado de la Real Hacienda del lugar durante todo el periodo, fue relatada en varios trabajos por Florencia Fajardo Terán $(1967,1977,1978)$. 
todo el espacio rioplatense, ${ }^{5}$ la ocupación del área de Maldonado era una pieza fundamental para lograrlo, y para eso era necesaria una política de poblamiento y de defensa militar del lugar que, como veremos, implicaba importantes erogaciones para la Real Hacienda.

De la misma manera que su establecimiento, el cese de actividades de la caja en 1806 y su desaparición definitiva la relacionan con el contexto más amplio de las crisis fiscales y políticas de la región y de la monarquía borbónica en su conjunto. Las invasiones inglesas obligaron a interrumpir las actividades de la caja en un primer momento, pero fueron el déficit fiscal de la Tesorería General y los sucesos políticos que sucedieron en la región luego de 1808 los que impidieron la reanudación de la política de poblamiento, que era la razón de ser de la institución.

Toda la documentación de la Caja Real de Maldonado era remitida a la Tesorería General de Buenos Aires para su control. Como no se han conservado en su totalidad hemos tenido que utilizar diferentes libros para completar la información del periodo. Así, para los años 1782-1787 y 17891802 se recabaron los datos contenidos en el Común General, y para 1788 y 1803-1806 se utilizó la información del Libro Mayor de Caja. ${ }^{6}$ La diferencia principal entre los dos tipos de libros consiste en que el primero brinda una información completa de cada asiento mientras que en el segundo los datos son más escuetos, remitiendo a la página correspondiente del Libro Manual de Caja. No obstante, cuando la información es escasa se puede recurrir al Libro Manual o a los comprobantes de cargo y data que se encuentran en las cajas.

\section{Ingresos de la CAja ReAl de Maldonado}

En este apartado se analizaran los ingresos de la Caja Real de Maldonado para determinar el origen de los caudales que se invertían en el área. Luego, en los apartados siguientes, se estudiarán por separado los gastos que ocasionaban la política de poblamiento y las erogaciones que implicaban los costos militares destinados a la defensa del territorio.

\footnotetext{
${ }^{5}$ La expulsión de los portugueses de Colonia de Sacramento en 1777 fue, sin duda, la manifestación más concreta de ese objetivo.

${ }^{6}$ Los libros se encuentran en la Sala XIII del Archivo General de la Nación Argentina (en adelante AGN) en cajas (una por año) que contienen, además de los libros ya mencionados, el juicio de la cuenta (que consta de la evaluación hecha por el Tribunal de Cuentas y la contestación de Pérez del Puerto a la misma), los libros auxiliares y todos los comprobantes de cargo y data. Las cajas se encuentran archivadas con la denominación Maldonado y números que van correlativamente del 3288 para 1782 hasta el 3312 para 1806.
} 
Como se sabe, las cuentas de la Real Hacienda se dividían en ramos. A su vez, estos se agrupaban en varios tipos: a) los de la masa común que eran de libre disponibilidad; b) los particulares de Real Hacienda, que estaban destinados a fines específicos y por lo general debían remitirse a la península; $c$ ) los particulares ajenos que consistían en caudales que administraba la Real Hacienda pero que en realidad no le pertenecían, y d) los ramos en los que se asentaban los resultados de la cuentas y por lo tanto reflejan operaciones contables y no ingresos o egresos reales de dinero. En consecuencia, en este trabajo solamente se hace referencia a los ramos de la masa común de la Real Hacienda.

Más de $86 \%$ de los ingresos de la masa común de Real Hacienda de la Caja Real de Maldonado durante los 25 años de su existencia procedían de los excedentes enviados desde otras tesorerías del virreinato (véase cuadro 1). La Caja Real de Montevideo remitió un total de 541883 pesos, la Tesorería General de Buenos Aires aportó 431 455, y el resto consistió en pequeños aportes recibidos por diversas situaciones. ${ }^{7}$

Esas tesorerías eran a su vez receptoras de fondos. De acuerdo con los datos de Samuel Amaral (2011, p. 400), 72\% de los ingresos de la Caja Real de Buenos Aires entre 1789 y 1809 eran producto de las remesas que se enviaban desde las cajas del Alto Perú. A su vez, Montevideo recibía una parte importante de los caudales que utilizaba de la capital virreinal. ${ }^{8}$ En consecuencia se puede decir que el dinero que arribaba a Maldonado procedía de los excedentes de las cajas de las zonas mineras del Alto Perú y solamente pasaba por las otras cajas del Río de la Plata. ${ }^{9}$ Por otro lado, a diferencia de Buenos Aires y Montevideo, la Caja Real de Maldonado sólo era receptora de fondos. Es decir, los caudales que llegaban se gastaban en el lugar sin la necesidad de remitir parte de los mismos a ninguna otra zona. $^{10}$

${ }^{7}$ Por ejemplo, el 26 de agosto de 1787 ingresaron 1772 pesos, seis reales y quince maravedíes procedentes de la Administración de los Pueblos Misioneros a cuenta de una recolección y conducción de cueros realizada en 1779. Por otro lado, el 2 de noviembre de 1799 se recibieron 17 pesos y cuatro reales que adeudaba la Tesorería de Santa Fe. Existieron, además, algunos traslados de fondos desde otros ramos que luego debían ser devueltos por la Tesorería General de Buenos Aires y por eso no los hemos descontado.

${ }^{8}$ Todavía no se conocen estudios sobre la Caja Real de Montevideo por lo que, por el momento, no podemos determinar cuál era la importancia del ramo Otras tesorerías en esa caja.

${ }^{9}$ Esta situación obliga a tener el recaudo de restar esas transferencias de los ingresos de cada caja, de lo contrario los mismos caudales se computan como ingreso en cada una de las cajas por las que pasaba.

${ }^{10}$ Dentro del ramo Otras tesorerías únicamente se registraron dos asientos de data: el 29 de diciembre de 1791 se restituyeron 2030 pesos y un real que se habían tomado de los ramos particulares y el día anterior se habían devuelto 1020 pesos a Miguel Antonio Aldaya, que el 20 de diciembre los había adelantado a cuenta del caudal que debía remitirse. Esas dos transferencias fueron las únicas que tuvimos que descontar del ramo Otras tesorerías (AGN. Sala XIII, 3297, Tribunal de Cuentas, Maldonado 1791, Libro Común General). 
CUADRO 1. CAJA REAL DE MALDONADO:

INGRESOS DE LA REAL HACIENDA EN COMÚN, 1782-1806

\begin{tabular}{lrr}
\hline Ramo & \multicolumn{1}{c}{ Pesos } & Porcentaje \\
& & \\
Otras tesorerías & 983646 & 86.65 \\
Alcabalas & 27603 & 2.43 \\
Pulperías & 23156 & 2.04 \\
Almojarifazgo & 7967 & 0.70 \\
Estancias & 50913 & 4.48 \\
Isla de Lobos & 3363 & 0.29 \\
Santa Teresa & 11264 & 0.99 \\
Hospital & 783 & 0.07 \\
Extraordinarios & 5493 & 0.48 \\
En común & 21294 & 1.87 \\
Total & 135482 & 100 \\
\hline
\end{tabular}

Fuente: elaboración propia con base en Libros Común General y Mayor de Caja de la Caja Real de Maldonado, AGN, Sala XIII, Tribunal de Cuentas, Maldonado, cajas 3288-3312.

A partir de 1797 la Caja Real de Maldonado se vio enmarcada dentro de las operaciones para financiar el déficit de la Tesorería General de Buenos Aires. La Caja Real de Buenos Aires se financiaba tomando fondos de los ramos particulares y de otras instituciones (como la Aduana o el Cabildo) para mantener al día los pagos hasta el arribo de los fondos enviados desde el Alto Perú (Amaral, 2011). La utilización de ese recurso se incrementaba en periodos de guerra, cuando se remitían fondos a la península para que la corona pudiera afrontar el incremento de los gastos militares. ${ }^{11}$ El reflejo de esa situación se observa en las cuentas de la Caja de Maldonado. Durante las guerras con Inglaterra se tomaban fondos de los diezmos, de particulares o de la Aduana de Buenos Aires y se libraban contra la Tesorería de Buenos Aires. Es decir, se recibían caudales de otros ramos e instituciones que debían ser devueltos en la capital virreinal. Por este mecanismo se evitaba un traslado innecesario de la plata amonedada con su correspondiente ahorro del costo de flete.

En consecuencia, la mayor parte de los pagos efectuados por la Caja Real de Maldonado se realizaban con ingresos provenientes de otras tesorerías del virreinato. Aunque no aportaban caudales significativos, los

${ }^{11}$ En 1797, por ejemplo, se enviaron desde la Caja Real de Buenos Aires 1873454 pesos a España (Amaral, 2011, p. 409). 
otros ramos que componían el cargo de la masa común de Real Hacienda en Maldonado revelan varios aspectos de la economía del área y del peso que la organización militar para la defensa de la frontera imperial tenía en la misma.

El total de los dineros aportados por la recaudación de los impuestos (alcabala, composturas de pulperías y almojarifazgo) apenas superó 5\% de los caudales disponibles. El tamaño reducido de esas cifras era la consecuencia lógica de la reciente ocupación del área que implicaba una densidad muy baja de la población y una reducida, aunque creciente, cantidad de transacciones.

A pesar de esa escasa relevancia como fuente de ingresos, el cobro de esos impuestos permite seguir anualmente el desempeño económico del comercio y la producción en el área. Por un lado, siguiendo la sugerencia de Garavaglia y Grosso $(1987$, pp. 48, 59) los montos percibidos por la recaudación de la alcabala pueden ser tomados como un indicador del grado de actividad económica del lugar. Por otro lado, permiten analizar la evolución de la producción agropecuaria, de las transacciones que involucraban esclavos y bienes inmuebles y de la presencia y permanencia de las pulperías en los distintos sitios del área (véase Biangardi, 2013a, 2013b). ${ }^{12}$ Además brindan la posibilidad de relacionar esos datos con la demanda que generaban los gastos que analizaremos en los apartados siguientes. La inusual continuidad en el tiempo de las pulperías establecidas en las inmediaciones del fuerte de Santa Teresa, por ejemplo, parece un claro indicador de las oportunidades de negocios que brindaba la presencia permanente de tropas.

Sin embargo, una comparación de la evolución anual de los ingresos provenientes de otras tesorerías con la de los que se generaban en la recaudación local de impuestos revela que no existía una relación directa entre los ramos (véanse gráficas 1 y 2). Es decir, un aumento de las remesas que llegaban al lugar no implicaba un aumento en la actividad económica que pudiera ser reflejado en la recaudación de ese mismo año. ${ }^{13} \mathrm{~A}$ pesar de esto sí se puede decir que, más allá de los vaivenes anuales a lo largo del tiempo, la recaudación crecía (véase línea de tendencia en gráficas 1 y 2). Para entender esta evolución es necesario recurrir a datos adicionales para determinar los factores que influyeron en estas variables. En primer 2013b)

${ }^{12}$ Ya hemos realizado estos análisis en otros trabajos a los que remitimos (Biangardi, 2013a y

${ }^{13}$ Es probable que esto sea una particularidad del caso de Maldonado por el predominio de los gastos de poblamiento por sobre los militares, que veremos más adelante. En las ciudades fortificadas donde los gastos militares eran más importantes seguramente se daba una mayor correlación entre las remesas recibidas y la recaudación de impuestos. Para el caso de Cartagena, véase Meisel (2000). 


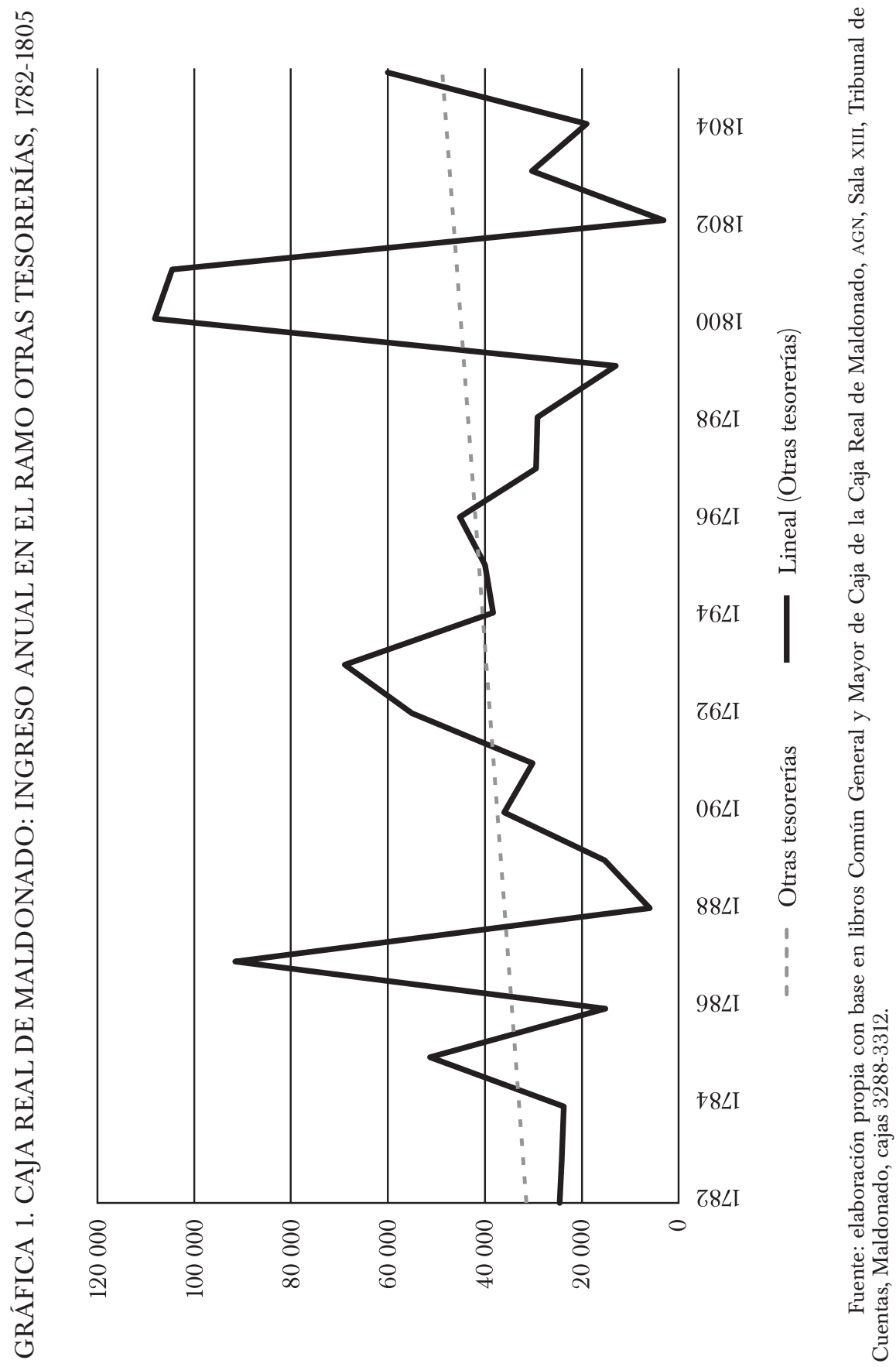




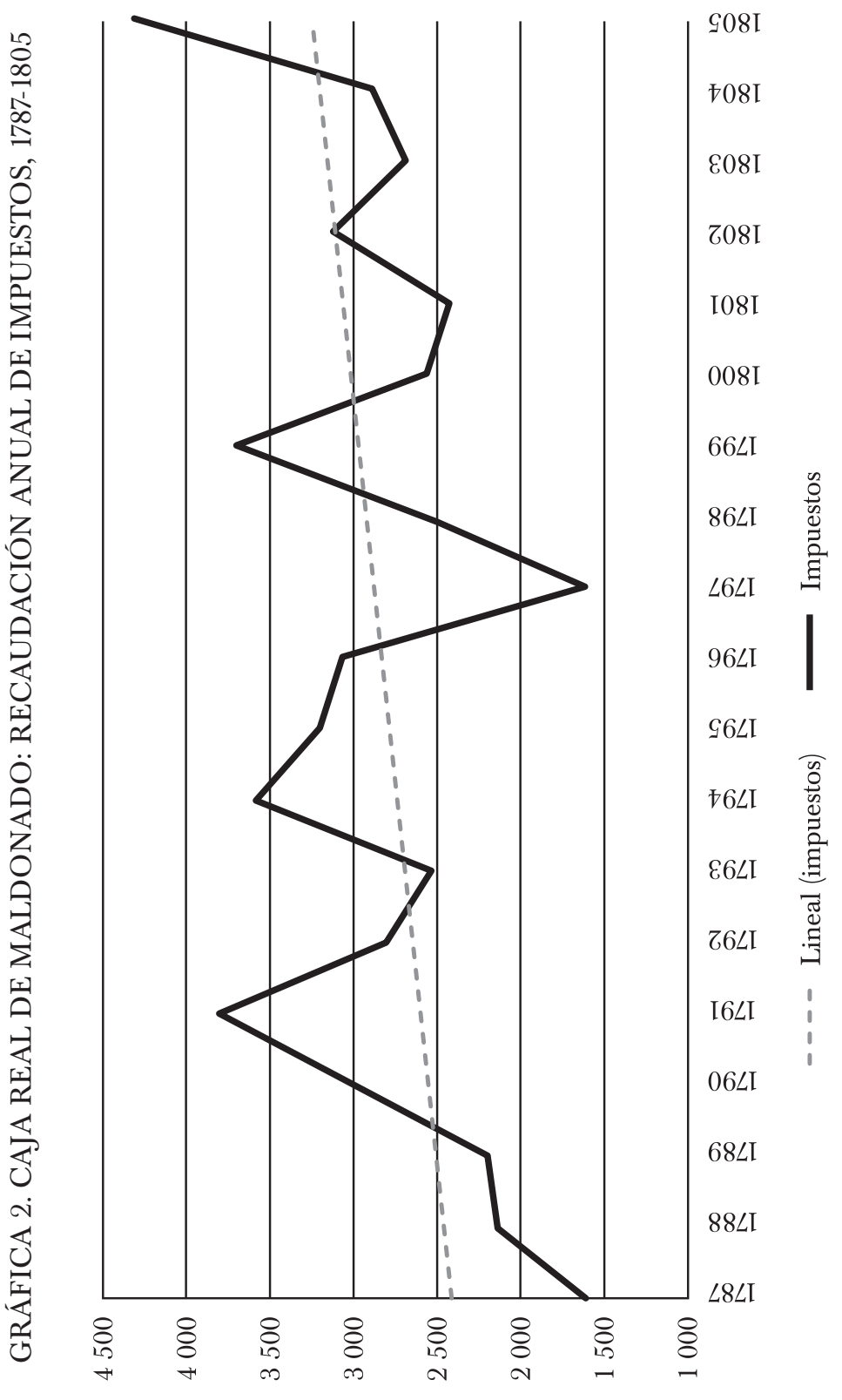

范 
lugar, el envío de remesas dependía de la existencia de excedentes en las cajas de origen, por lo que las alzas y bajas anuales (véase gráfica 1) no se corresponden necesariamente con las obligaciones que debía enfrentar la caja de Maldonado. De todas maneras, al tener una capacidad reducida para hacerse de recursos propios, los gastos estaban determinados por la posibilidad de recibir esos caudales. Es decir, durante los años en los que no ingresaban caudales desde otras tesorerías se acumulaban deudas que se pagaban en los años siguientes, como se verá al analizar los gastos. En segundo lugar, en el caso de la recaudación de impuestos el principal factor determinante estaba constituido por las vicisitudes del comercio ultramarino. Las principales caídas en la recaudación ocurrieron como consecuencia de los inconvenientes que las guerras contra Inglaterra ocasionaban al comercio legal dentro de la monarquía española durante los años 1797 y 1800-1801 (véanse gráficas 2 y 3).

Tomamos la recaudación de impuestos desde 1787 porque es en ese año cuando comienzan a cobrarse las composturas de pulperías y, por ende, la inclusión de los años anteriores daría una falsa impresión de un crecimiento de la actividad económica que en realidad fue un aumento de la base imponible. En los años 1782-1786 se considera solamente la recaudación de las alcabalas (véase gráfica 4). Por otra parte, descartamos el año 1806 para considerar solamente años enteros. ${ }^{14}$

La gráfica 3 muestra la recaudación de impuestos sin el almojarifazgo porque la inclusión de este disminuye los efectos de la guerra en la recaudación, ya que se cobró de forma esporádica y, especialmente, sobre bienes confiscados en tiempos de guerra. La recaudación de la alcabala refleja claramente esta situación, y aun las composturas de pulperías que constituían un ingreso más estable también lo hacen (véanse gráficas 4 y 5). Por último, el alza de la recaudación a lo largo del tiempo que indican las tendencias lineales de las gráficas se puede explicar, en cambio, por el crecimiento económico del área producto de la ocupación de nuevas tierras y del aumento poblacional, que ya he mostrado en otro trabajo (Biangardi, 2013a). ${ }^{15}$ En consecuencia, no hay una relación directa entre la inyección de metálico en el área por parte de la Real Hacienda y el crecimiento económico. Sin embargo, al analizar la distribución del gasto se podrá observar que en este caso ese dinero ayudó a consolidar el asentamiento de trabajadores en el área, aumentando la cantidad de trabajo disponible y alentando la ocupación de nuevas tierras. Otros gastos como

\footnotetext{
${ }^{14}$ Recordemos que la ocupación de Maldonado por las tropas inglesas implicó el final de la actividad de la caja en agosto de ese año.

${ }^{15}$ Ese crecimiento económico parece darse en toda la región. Recientemente Daniel Santilli (2013) ha destacado la importancia de las reformas borbónicas en el crecimiento de Buenos Aires durante esos años.
} 


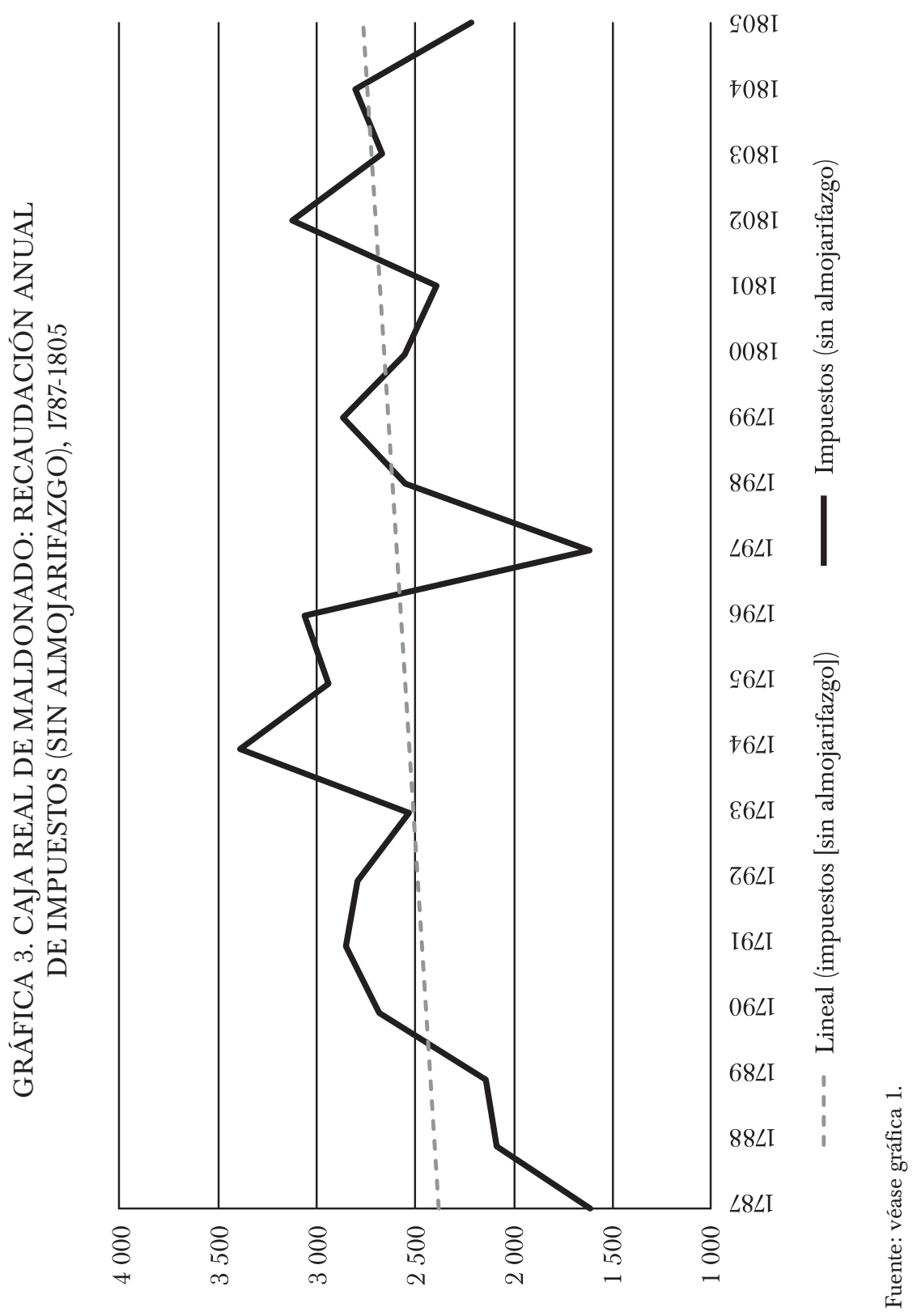




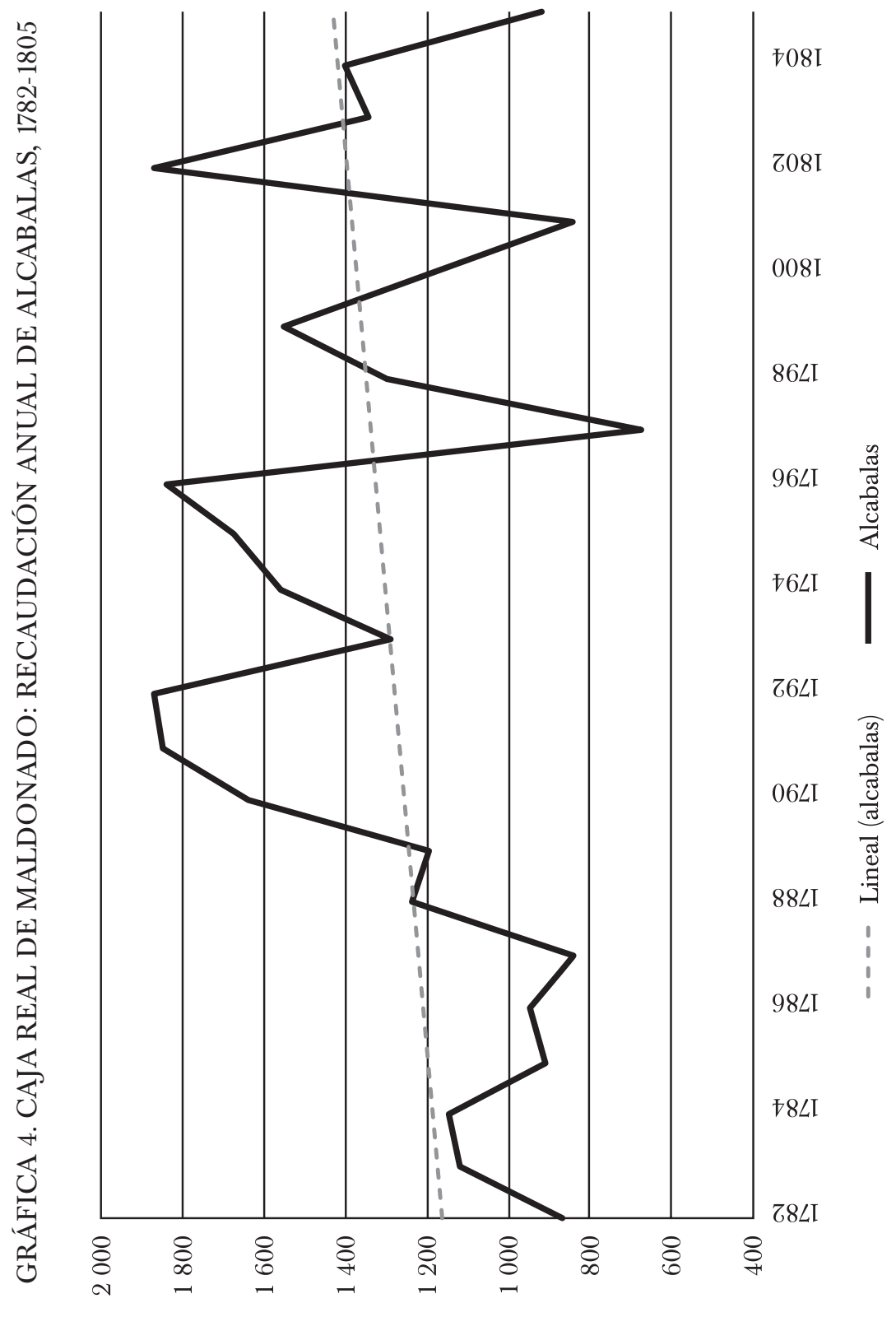

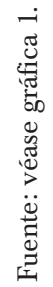




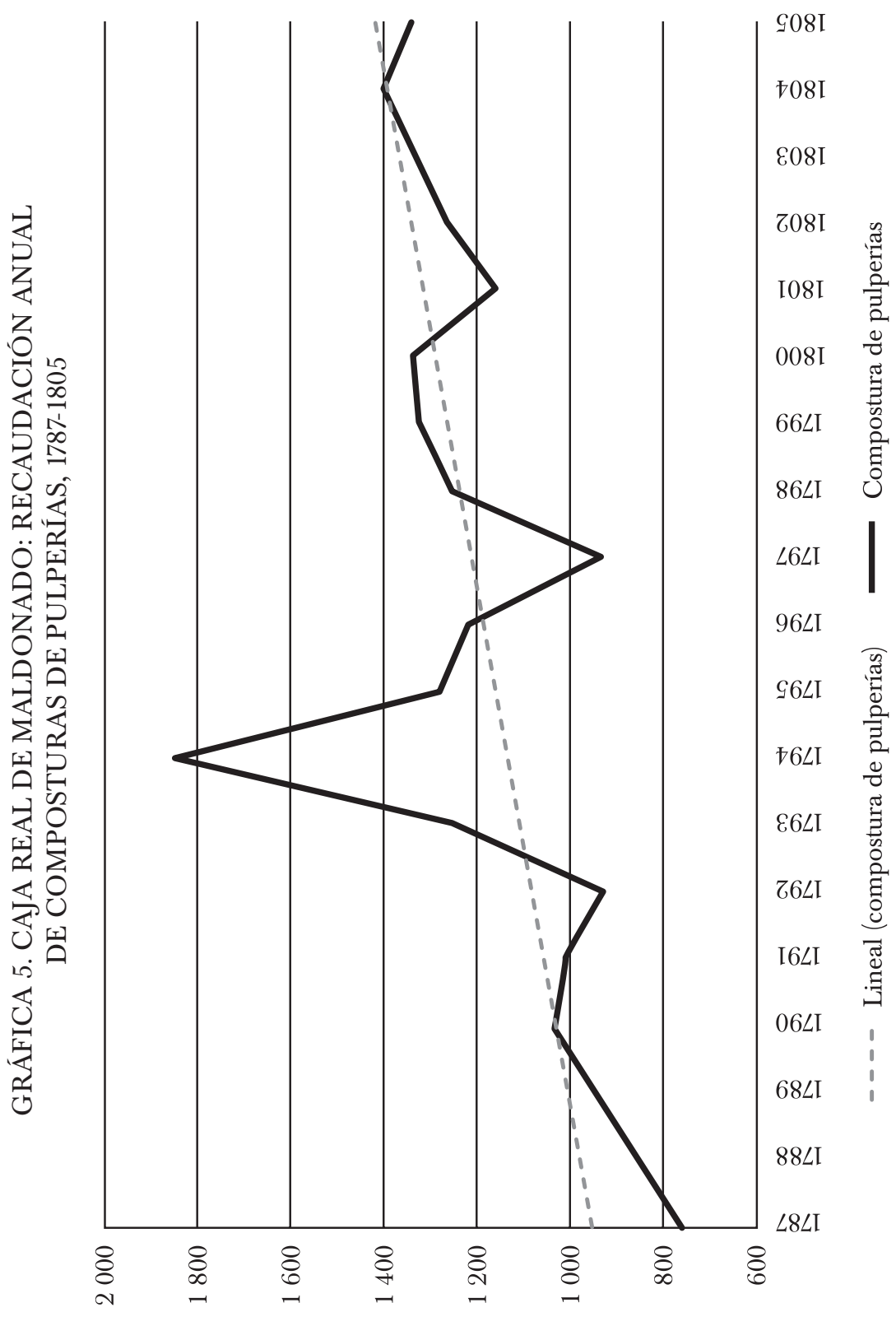

范 
los salarios militares podían generan oportunidades de negocios para algunos comerciantes, como se puede observar en la ubicación y duración en el tiempo de algunas pulperías, y también generaban una demanda de bienes que podía dinamizar la economía local en ese momento pero no necesariamente generaban un crecimiento de la economía del área.

Por su parte, las estancias del rey aportaban unos ingresos similares a la recaudación de impuestos. En realidad las ganancias que producían eran muy pocas, ya que se gastaba una suma equivalente en salarios. Sin embargo, esas estancias no estaban orientadas al mercado, sino que tenían como objetivo criar caballos, bueyes y vacas para abastecer de transporte y alimento a las tropas establecidas en el área. ${ }^{16}$ La mayor parte de lo asentado en el cargo del ramo Estancias, lo mismo que en el denominado como Santa Teresa, corresponde a los descuentos en los sueldos de peones y soldados por el suministro cotidiano de carne fresca. Los ingresos de la venta de los cueros producidos por esas reses se encuentran asentados hasta 1786 en el ramo Extraordinarios y luego se los incluye en el de Estancias. Antes de 1787 se realizaron tres ventas de cueros que generaron un total de 4003 pesos y cinco reales. ${ }^{17}$ Luego se continuaron vendiendo cueros y novillos a particulares de forma esporádica sin llegar nunca a implicar un monto significativo de dinero. ${ }^{18}$ Por otro lado, una parte importante de los cueros, sebo y grasa producidos se consumía en diferentes atenciones. Esos consumos están asentados como ingresos en el ramo Estancias y luego lo mismo se indicaba como gasto en el ramo Gastos generales, con lo que no implicaban un ingreso real de dinero, aunque sí una reducción de costos al no tener que comprar esos insumos a los estancieros del lugar.

En el ramo Isla de Lobos se asentó la ganancia producida en los años 1787 y 1791, durante los cuales la Real Hacienda se hizo cargo de las faenas de cuero y sebo de lobos marinos realizadas en la denominada Isla de

${ }^{16}$ Existieron cuatro estancias del rey en el área: la de Pan de Azúcar, especializada en la cría de caballos; las situadas en el arroyo Don Carlos y en José Ignacio, dedicadas a la cría de ganado vacuno, y por último la estancia contigua al fuerte de Santa Teresa, destinada a cubrir las necesidades de ese establecimiento militar (Díaz de Guerra, 1988, pp. 304-307).

${ }^{17}$ El 28 de octubre de 1783 se vendieron en pública subasta los cueros faenados en la estancia del rey Don Carlos a José Trigo por 1531 pesos y cinco reales a razón de catorce reales la pesada de 41 libras (AGN. Sala XIII, 3289, Tribunal de Cuentas, Maldonado 1783, Libro Común General). El 28 de septiembre de 1785 se vendieron 500 cueros a Francisco Martínez Moldes por 625 pesos (AGN. Sala XIII, 3291, Tribunal de Cuentas, Maldonado 1785, Libro Común General). El 17 de junio de 1786 se vendieron 1900 cueros de toro, novillo y vaca a Miguel Ramos por 1847 pesos (AGN. Sala XIII, 3292, Tribunal de Cuentas, Maldonado 1786, Libro Común General).

${ }^{18}$ En 1789, por ejemplo, solamente ingresaron 291 pesos por las ventas de cueros. En 1792 no se vendieron cueros pero la venta de 800 novillos a José Antonio Medina generó 1400 pesos (AGN. Sala XIII, 3295, Tribunal de Cuentas, Maldonado 1789, Libro Común General). 
Lobos, que se encuentra situada en las cercanías de Maldonado. ${ }^{19}$ El resto de los ingresos se corresponde a pequeños cobros por fletes incluidos en el ramo Extraordinarios y otros por atenciones en el Hospital de Maldonado. Finalmente, a partir de 1803, en los libros mayores de caja se dejaron de usar estos ramos y se consignaban todas las entradas por provisiones de carne, cueros y sebo, las hospitalidades e ingresos extraordinarios dentro de un solo ramo que simplemente se denominaba Real Hacienda en común.

En síntesis, los ingresos de la Caja Real de Maldonado durante los 25 años en los que se mantuvo en funcionamiento estuvieron compuestos en $86.65 \%$ por los caudales recibidos desde otras tesorerías, $5.17 \%$ por los dineros percibidos mediante la recaudación local de impuestos y el 8.18\% restante por ingresos provenientes de distintos conceptos, entre los que se destacaba la producción de la estancias del rey situadas en el área.

\section{Distribución del gasto en la Caja Real de Maldonado}

La composición de los egresos es reveladora sobre los objetivos a los que respondían los envíos de esos importantes caudales y, en última instancia, de los motivos de la existencia misma de la Real Caja de Maldonado. El gasto fiscal realizado por la corona indica, además, la importancia estratégica del área dentro del entramado del sistema defensivo de los dominios americanos de la monarquía española.

El cuadro 2 muestra los gastos por ramos tal como aparecen en los libros de la caja. Se observa a simple vista que los gastos militares y los destinados a la política de poblamiento predominan. Los criterios para asentar algunos gastos en un ramo u otro no eran claros y fueron cambiando. En los libros de un año aparece el ramo Obras y al año siguiente los gastos vinculados a obras están consignados en el ramo Extraordinarios. En este sentido, los ramos Gastos generales y Extraordinarios son verdaderas cajas de Pandora donde se pueden encontrar situaciones de todo tipo. En consecuencia, luego de estudiar todos los asientos contables de cada libro de caja, se pudo conseguir una clasificación de los gastos según su destino (véase cuadro 3$).{ }^{20}$

${ }^{19}$ Los cueros de lobos marinos eran una de las mercancías que se enviaban desde Maldonado hacia el puerto de Montevideo durante todo el periodo, de manera que, salvo por esos dos años, las faenas eran llevadas a cabo por particulares (Biangardi, 2013a, pp. 21-23).

${ }^{20}$ Hemos considerado como parte de la administración civil los sueldos de los encargados de la administración de la caja, del hospital, del cirujano, del baqueano, de los capataces y peones de las carretas del rey, de la boyada, del matadero y de la lancha del puerto Maldonado y los capataces y peones de las estancias del rey de Pan de Azúcar, Don Carlos y José Ignacio. Así como 
CUADRO 2. CAJA REAL DE MALDONADO: GASTOS DE LA REAL HACIENDA EN COMÚN POR RAMOS FISCALES, 1782-1806

\begin{tabular}{lrc}
\hline Ramo & Pesos & Porcentaje \\
& & \\
Familias pobladoras & 547672 & 46.11 \\
Santa Teresa & 119717 & 10.08 \\
Sueldos & 140191 & 11.8 \\
Sueldos militares & 122648 & 10.32 \\
Estancias & 65808 & 5.54 \\
Hospital & 13415 & 1.12 \\
Obras & 26024 & 2.19 \\
Fortificaciones & 12613 & 1.06 \\
Extraordinarios & 106626 & 8.98 \\
Gastos generales & 33252 & 2.8 \\
Total & 187966 & 100 \\
\hline
\end{tabular}

Fuente: véase cuadro 1 .

CUADRO 3. CAJA REAL DE MALDONADO: DESTINO DE LOS GASTOS DE LA REAL HACIENDA EN COMÚN, 1782-1806

\begin{tabular}{lrc}
\hline Destino & Pesos & Porcentaje \\
& & \\
Poblamiento & 582231 & 49 \\
Militar & 343627 & 29 \\
Administración & 262108 & 22 \\
Total & 1187966 & 100 \\
\hline
\end{tabular}

Fuente: véase cuadro 1.

Los gastos administrativos tuvieron una cierta constancia en todo el periodo, con un leve incremento luego de 1797, más allá de los gastos extraordinarios del año 1801, cuando fue necesario comprar grandes cantidades de animales para reponer el stock de ganado de las estancias del rey (véase gráfica 6). Los gastos de poblamiento, por su parte, se mantuvieron

los gastos generales y extraordinarios que esas actividades generaron. El resto de los asientos de data correspondientes a la Real Hacienda en común de los libros de la Caja, fueron considerados como parte de los gastos de poblamiento o militares. 


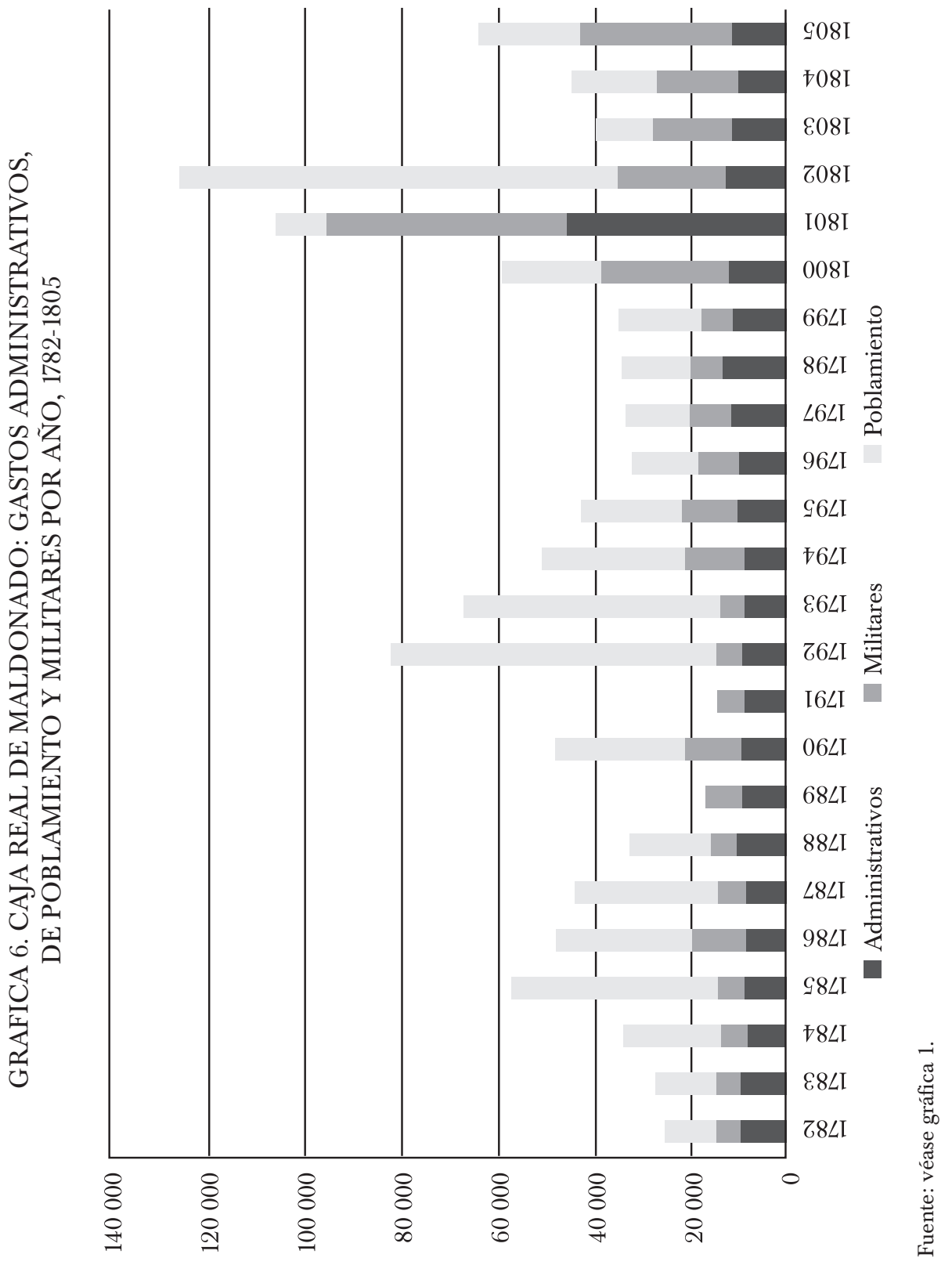


altos durante todo el periodo, con caídas debidas a la falta de fondos que se compensaban con incrementos importantes cuando se saldaban las deudas, como en los años 1792-1793 y 1802.

Por último, los gastos militares se mantuvieron estables hasta que se vieron notablemente incrementados por las guerras contra Inglaterra, especialmente a partir de 1800. En los primeros tres años de guerra (17971799) la Caja de Maldonado recibía caudales del ramo de Guerra ${ }^{21}$ destinados al pago de las compañías de Blandengues. ${ }^{22}$ Es probable que eso explique la falta de incremento de los gastos militares en esos tres años; a partir del año siguiente la caja comienza a pagar sueldos militares, como veremos más adelante. En las páginas siguientes se realiza un análisis detallado de los gastos de poblamiento y de las erogaciones militares para ver de qué manera esos gastos podían influir en la economía local.

\section{Gastos de poblamiento}

Cerca de la mitad de las erogaciones de la Caja Real de Maldonado correspondía a lo registrado en el ramo Familias pobladoras y poblaciones (véase cuadro 2). Las denominadas familias pobladoras habían llegado al Río de la Plata como parte de proyectos de poblamiento situados en la costa patagónica. Luego del fracaso de los pueblos proyectados, esas familias fueron destinadas a los distintos espacios fronterizos de la región Río de la Plata. ${ }^{23}$

Casi la totalidad de los gastos asentados en el ramo (473 890 pesos y un real de los 547672 pesos y dos reales) fue consecuencia de un estipendio mensual que se les abonaba a los pobladores a razón de un real por día a cada persona para su alimentación, como equivalente a una ración, y dos pesos por mes a cada familia para abonar el alquiler de una casa. La corona estaba comprometida a brindar esta ayuda monetaria hasta un

${ }^{21} \mathrm{El}$ ramo de Guerra era un impuesto municipal y, por ende, un ramo particular ajeno, por lo que no fue considerado como parte de los gastos militares de la caja.

${ }^{22}$ La Compañía de Blandengues de Montevideo fue creada en 1797 por el virrey Pedro de Melo. Los blandengues eran una fuerza de caballería veterana a cargo de la seguridad de la frontera, lo que incluía el combate contra el contrabando. Era financiada por medio de un impuesto municipal cobrado sobre los cueros exportados, denominado ramo de Guerra. Los blandengues de Montevideo fueron creados a imitación de los que ya existían en Buenos Aires desde 1752. Estos habían iniciado como milicias asalariadas pero en 1784 habían sido transformados en fuerzas veteranas. Debido a que eran insuficientes para controlar las amplias fronteras rioplatenses, los funcionarios buscaban articular esas compañías con fuerzas de caballerías milicianas. Raúl Fradkin (2015) sostiene que uno de los objetivos consistía en que los blandengues veteranos contribuyeran a disciplinar a las caballerías milicianas.

${ }^{23}$ Sobre el aporte demográfico de esas familias al poblamiento de la Banda Oriental véase Apolant (1970). 
año después de que cada familia lograra su establecimiento definitivo. La situación de depósito temporario de los pobladores se prolongó, en primer lugar debido al fracaso del proyecto de poblamiento de la costa patagónica y a que luego las guerras obligaron a desviar fondos hacia los gastos militares, retrasando de esa manera la formación de los pueblos a los que se los iba a destinar. En consecuencia los pobladores recibieron el estipendio mensual por un tiempo mayor al previsto, lo que incrementó de manera significativa el gasto que ocasionaba para la Real Hacienda.

Los asientos contables del ramo Obras y algunos de los que figuran en Extraordinarios y en Gastos generales permiten mensurar el costo y el tiempo que implicaba formar un pueblo desde cero. En 1783, una vez finalizada la guerra con Inglaterra, se emprendió la fundación de la villa de Concepción de Minas, a la que se destinaron 40 de las familias pobladoras.

La particularidad de la formación del pueblo de Minas consistió en que la Real Hacienda gestionó de manera directa la construcción de una casa para cada familia destinada al lugar, además de la iglesia y el cabildo cárcel y guardia del futuro poblado. La construcción de esos edificios requirió una movilización considerable de recursos materiales y de trabajadores. Las obras fueron realizadas por los jefes de familia de las familias pobladoras, 150 indios misioneros trasladados especialmente para ese fin y varios trabajadores especializados (Fajardo, 1958, pp. 129-130). Para ello, a lo largo de cinco años se destinaron 19693 pesos, un real y siete maravedíes en asignaciones mensuales de los indios y jornales de los trabajadores y 7668 pesos, cinco reales y 29 maravedíes en provisiones para las raciones diarias y algunas prendas de vestir (véase cuadro 4$){ }^{24}$ Por su parte, los maestros albañiles recibieron 4900 pesos por la construcción de las casas. ${ }^{25}$ Además, se compraron puertas, ventanas, herrajes, tejas y distintos enmaderados a herreros, fabricantes de tejas y carpinteros por un

${ }^{24}$ Podemos dar algunos ejemplos de esas compras. El 15 de mayo de 1783 se compraron a Antonio José Méndez tres arrobas de ají a ocho pesos y cuatro reales cada arroba, y el 19 de septiembre al mismo vendedor 28 arrobas de yerba mate a 26 reales la arroba. El 18 de julio de ese mismo año José Trigo proporcionó 51 reses a dos pesos cada una porque el mal tiempo impedía trasladar ganado de las estancias del rey (AGN. Sala XIII, 3289, Tribunal de Cuentas, Maldonado 1783, Libro Común General). El 14 de junio de 1784 se abonaron 117 pesos y cuatro reales por nueve arrobas y diez libras de tabaco. Los días 20 de junio y 11 de agosto del mismo año se compró un total de 46 quintales y 83 libras de bizcocho a varios vecinos de Maldonado (AGN. Sala XIII, 3290, Tribunal de Cuentas, Maldonado 1784, Libro Común General).

${ }^{25}$ La suma fue abonada en tres pagos. El 16 de diciembre de 1783 los albañiles recibieron 2660 pesos por la hechura de las paredes de las 40 casas a razón de cuatro reales cada vara de pared, el 12 de marzo de 1784, 640 pesos por las paredes de las cocinas, y el 20 de mayo del mismo año, 1600 pesos por el techo y revoque a la cal de las casas (AGN. Sala XIII, 3289, Tribunal de Cuentas, Maldonado 1783, Libro Común General). 


\section{CUADRO 4. GASTOS OCASIONADOS EN LA CONSTRUCCIÓN DE LA VILLA DE MINAS}

\begin{tabular}{lrrr}
\hline Destino & Pesos & Reales & Maravedies \\
Jornales & & & 7 \\
Provisiones & 19693 & 1 & 29 \\
Albañiles & 7668 & 5 & 0 \\
Tejas & 4900 & 0 & 0 \\
Carpinteros & 980 & 5 & 0 \\
Herreros & 960 & 0 & 0 \\
Fletes & 340 & 1 & 0 \\
Total & 162 & 0 & 36 \\
\hline
\end{tabular}

Fuente: véase cuadro 1 .

total de 2280 pesos y seis reales. ${ }^{26}$ Finalmente, también se abonaron 162 pesos en concepto de fletes de materiales, víveres y personas. Es decir, la construcción del pueblo de Minas le costó a la Real Hacienda un total de 34704 pesos cuatro reales y 29 maravedíes.

Luego de la experiencia de la formación de la villa de Minas, la Caja Real de Maldonado optó por no hacerse cargo directamente de las construcciones y prefirió dar a los pobladores el equivalente en dinero del costo de la construcción de las casas que se les debía suministrar. Con ese objetivo, en 1792 se construyó una casa en Maldonado como modelo para conocer su costo, que fue finalmente de 472 pesos y siete reales. En consecuencia, entre 1793 y 1804 se abonaron 46460 pesos y cuatro reales a los pobladores, tanto a los que quedaron en Maldonado y San Carlos como a los que se trasladaron a la nueva villa de Rocha, en concepto de las casas que les correspondían.

Por otro lado, el Ministro de Real Hacienda, dentro de sus funciones de gestor de la política de poblamiento, tenía atribuciones para otorgar tierras en usufructo, por lo que se repartieron tierras entre las familias po-

${ }^{26}$ El 15 de noviembre de 1783 se pagaron 240 pesos al maestro herrero de Montevideo Domingo Basail por 40 cerraduras de puerta y 240 alcayatas. El 22 de noviembre del mismo año el maestro carpintero Ignacio Rodríguez recibió 440 pesos por 80 puertas y 40 ventanas (AGN. Sala XIII, 3289, Tribunal de Cuentas, Maldonado 1783, Libro Común General). El 16 de abril de 1784 se abonaron 520 pesos por los enmaderados de las casas y cocinas. El 10 de agosto se pagaron 980 pesos y cinco reales a José Trigo por 160000 tejas y 325 tejones. Finalmente, el 20 del mismo mes el maestro herrero Ignacio Taquín cobró 100 pesos y un real por el herraje hecho para los edificios de la cárcel, guardia y cabildo (AGN. Sala XIII, 3290, Tribunal de Cuentas, Maldonado 1784, Libro Común General). 
bladoras y se les proporcionó instrumentos de labranza y semillas para que pudieran comenzar a cultivar. De esta manera, en 1784 se entregaron 44 rejas de arar y 140 fanegas de trigo para semilla a las familias destinadas a la villa de Minas. ${ }^{27}$ Además, las familias recibieron un total de 364 pesos como equivalentes al precio de una yunta de bueyes, un arado y un yugo. Ese mismo año se repartieron también 139 fanegas de trigo entre las familias provisionalmente depositadas en Maldonado y 124 fanegas y tres cuartillas del mismo cereal entre las familias pobladoras que residían temporariamente en la villa de San Carlos. Por último, el 17 de julio de 1804 se le pagó 741 pesos y tres reales a Miguel de Yarza para distribuir a los pobladores de Rocha como equivalentes a las semillas y útiles que había que suministrarles.

Además, la Real Hacienda aseguró durante 20 años (desde 1786 hasta 1806) los servicios religiosos a los pobladores pagando 57 pesos anuales de gastos de la capilla situada en la villa de Minas y 168 pesos anuales de sueldo al presbítero encargado de la misma, que totalizan 4500 pesos. Adicionalmente se utilizaron 8000 pesos para la construcción de la iglesia de San Fernando de Maldonado y 5807 pesos, tres reales y 17 maravedíes para la obra de la iglesia de la villa de San Carlos. ${ }^{28}$

Por último, en el año 1804 se produjeron gastos variados como consecuencia de la fundación de Rocha y de los nuevos pueblos que se pretendían formar en la zona de Batoví, que significaron una erogación total de 6104 pesos y cuatro reales. La guerra, especialmente la invasión inglesa, y la crisis fiscal de los últimos años del virreinato, interrumpieron esos proyectos o al menos dieron por tierra la ayuda monetaria de la Real Hacienda a los mismos.

En síntesis, durante los 25 años transcurridos entre 1782 y 1806 la política de poblamiento en el área de Maldonado ocasionó gastos por un total de 582231 pesos, dos reales y doce maravedíes, lo que representaba prácticamente la mitad de los gastos totales de la Caja Real de Maldonado durante todo el periodo. El resto de las erogaciones de la institución se

${ }^{27}$ El 15 de agosto de 1784 el herrero Ignacio Yaquino recibió 88 pesos por 44 rejas de arar. El 18 del mismo mes se pagaron 490 pesos a Manuel Troncoso por las 140 fanegas de trigo (AGN. Sala XIII, 3290, Tribunal de Cuentas, Maldonado 1784, Libro Común General).

${ }^{28}$ El 13 de diciembre de 1794 se entregaron 3000 pesos al cura de la villa de San Carlos, Manuel Amenedo y Montenegro, para que pudiese continuar la obra de la iglesia (AGN, Sala XIII, 3300, Tribunal de Cuentas, Maldonado, 1794, Libro Común General). El 12 de noviembre de 1799 se le proporcionaron otros 2807 pesos, tres reales y 17 maravedíes con el mismo fin. Los días 7 de noviembre de 1800 y 24 de octubre de 1803 se entregaron 6000 y 2000 pesos, respectivamente, a Manuel Antonio Fajardo, mayordomo de la fábrica de la iglesia de San Fernando de Maldonado, para los gastos de la obra de dicha iglesia (AGN. Sala XIII, 3305, Tribunal de Cuentas, Maldonado 1799, Libro Común General; AGN. Sala XIII, 3306, Tribunal de Cuentas, Maldonado 1800, Libro Común General; y Libro Común General; AGN. Sala XIII, 3309, Tribunal de Cuentas, Maldonado 1803, Libro Mayor de Caja). 
debía a los gastos militares que se incrementaban considerablemente en los periodos de guerra y a los gastos ocasionados por el mismo funcionamiento de la caja.

\section{GASTOS MILITARES}

Debido a sus particularidades geográficas, el área de Maldonado era un punto estratégico para la defensa militar del territorio dominado por la monarquía española en América. En primer lugar, el puerto de Maldonado dominaba la entrada al Río de la Plata permitiendo controlar gran parte del tráfico de embarcaciones que entraban y salían del estuario ${ }^{29} \mathrm{En}$ segundo lugar, la zona poseía un amplio frente de costero marítimo apto para cualquier desembarco. Por último, el área formaba parte de un gran espacio de frontera, en este caso terrestre y marítima, con los territorios dominados por la corona portuguesa. Este conjunto de situaciones explica el envío de caudales desde otras tesorerías del virreinato y el peso que tuvieron los gastos militares dentro de las erogaciones de la Caja Real de Maldonado.

Los gastos militares pueden dividirse en dos tipos: los ordinarios, ligados a la defensa permanente del territorio, y los extraordinarios, que eran producto de acciones derivadas de los distintos conflictos bélicos en los que se vio involucrada la monarquía en esos años.

El funcionamiento del fuerte de Santa Teresa generaba prácticamente la totalidad de los gastos militares ordinarios. Las erogaciones incluían varios conceptos, por ejemplo, raciones a los presidiarios, sueldos (del capellán, del cirujano, de capataces y peones) y gastos de la capilla y del hospital. Por sí mismo el funcionamiento del fuerte durante los 25 años estudiados requirió 119717 pesos, seis reales y 21 maravedíes, lo que implicó $10.08 \%$ de los gastos totales de la Caja Real de Maldonado (véase cuadro 2) y, como veremos, aproximadamente un tercio de los gastos militares.

Las guerras incrementaban considerablemente los gastos militares. Esa situación se sentía especialmente con fuerza en determinados años. La erogación más importante dentro de los gastos militares extraordinarios eran los sueldos que se debían pagar por la movilización de las compañías de milicias. Los sueldos militares comenzaron a pagarse en febrero de 1798 y entre ese momento y la fecha de cierre de la caja de Maldonado por la

\footnotetext{
${ }^{29}$ Fernando Jumar (2012, p. 127) ha descrito el lugar del puerto de Maldonado como parte integrante del complejo portuario rioplatense. Este complejo permitía el normal funcionamiento del tráfico, subsanando las complicadas condiciones de navegación del Río de la Plata, a partir de la integración y articulación de los distintos puertos y desembarcaderos.
} 
invasión de las tropas inglesas en septiembre de 1806 totalizaron 122648 pesos, cinco reales y catorce maravedíes, lo que representaba $10.32 \%$ del total de la data de la masa común de Real Hacienda (véase cuadro 2). Esos sueldos constituyeron una erogación significativa especialmente durante 1801, cuando alcanzaron los 35164 pesos, cuatro reales y un maravedí, y 1805, cuando llegaron a 23311 pesos, seis reales y catorce maravedíes.

Los sueldos militares eran recibidos por distintas compañías de milicias y algunos individuos empleados en diferentes servicios (véase cuadro 5). La mayor parte de los sueldos devengados (88 081 pesos y tres reales) se destinó al Regimiento de Voluntarios de Caballería de Maldonado. En segundo lugar en importancia se encuentran los 20719 pesos y cinco reales abonados como salarios al Regimiento de Voluntarios de Caballería de la Colonia de Sacramento. Luego encontramos gastos vinculados a las baterías que protegían al puerto de Maldonado: 4836 pesos en concepto de salarios pagados a la milicia de artillería, 1342 pesos sueldos mensuales al carpintero, 420 pesos en salarios del guardaparque y 1297 pesos en gastos ocasionados por los indios, todos destinados al tren de batalla. Además se abonaron 1191 pesos, cinco reales y 33 maravedíes de los sueldos de la Compañía de Indultados y 3344 pesos a los empleados del hospital militar que funcionó de manera paralela al ya mencionado entre los gastos de la administración civil.

Los otros gastos militares también se incrementaban considerablemente durante los periodos de guerra y constituyeron erogaciones por un total de 101261 pesos, dos reales y 24 maravedíes. De esa suma 12613 pesos y cuatro reales se encuentran asentados en el ramo Fortificaciones, corresponden a las erogaciones producto de la construcción de baterías en la isla Gorriti en los años 1794, 1797 y 1801, y a la edificación de un almacén para la pólvora en 1795 . El monto restante se encuentra dentro los egresos extraordinarios e incluye varios destinos: construcción de edificios militares, reparación del cuartel de Maldonado y de los fuertes de Santa Teresa y San Miguel, raciones a indios o prisioneros ingleses, compra de animales y sueldos a peones. ${ }^{30}$

En consecuencia, si se suman las erogaciones causadas por el funcionamiento del fuerte de Santa Teresa, los sueldos militares y las obras de

${ }^{30}$ Los ejemplos son muy numerosos pero podemos dar algunos para brindar una idea de la variedad de los gastos militares extraordinarios. En 1782 se pagaron 125 pesos, seis reales y 18 maravedíes a los peones de las carretas del rey que se habían aumentado por la proximidad de los enemigos. En 1795 y 1796 se gastaron 9267 pesos, un real y 17 maravedíes en las obras de refacción de los fuertes de Santa Teresa y San Miguel y en la reedificación de los cuarteles de Maldonado. El 28 de diciembre de 1801 se abonaron 3489 pesos y cuatro reales a varios individuos por los gastos causados en la construcción de varias obras para el alojamiento de tropas. Existieron, además, muchos gastos en raciones para los indios y para los prisioneros ingleses, así como gastos vinculados a la armería y a la artillería, que sería muy extenso detallar. 


\section{CUADRO 5. CAJA REAL DE MALDONADO: RAMO SUELDOS MILITARES, 1798-1806}

\begin{tabular}{lrcc}
\hline Destino & Pesos & Reales & Maravedíes \\
Caballería de Maldonado & 88081 & 3 & 0 \\
Caballería de Colonia & 20719 & 5 & 0 \\
Milicia de artillería & 4836 & 0 & 0 \\
Milicia de Rocha & 1416 & 3 & 32 \\
Compañía de Indultados & 1191 & 5 & 33 \\
Empleados del hospital & 3344 & 0 & 0 \\
Indios & 1297 & 0 & 0 \\
Carpintero & 1342 & 0 & 0 \\
Ayudante de guarda & 420 & 0 & 0 \\
Total & 122646 & 16 & 65 \\
\hline
\end{tabular}

Fuente: véase cuadro 1 .

fortificaciones, reparaciones de fuertes y edificios militares, y algunos otros egresos producto de los contextos bélicos obtenemos que los gastos militares totales de la Caja Real de Maldonado durante los 25 años estudiados fueron 343627 pesos, seis reales y 25 maravedíes. Esos gastos representaban un poco más de un cuarto de los gastos totales de la caja.

\section{CONSIDERACIONES FINALES}

En síntesis, a partir de los datos disponibles en los libros de la Real Caja de Maldonado se puede afirmar que la Real Hacienda invirtió 1187966 pesos en el área durante un periodo de 25 años. $49 \%$ de esos egresos fue consecuencia de la política de poblamiento emprendida en la zona, 29\% se destinó a la defensa militar del territorio y $22 \%$ a gastos administrativos (véase cuadro 4). Todas las erogaciones realizadas por la institución implicaron una inyección constante de metálico en el área que permitió consolidar su ocupación y estimuló su crecimiento económico.

En este sentido es necesario aclarar que no existía una relación directa entre gasto fiscal y crecimiento económico. En el texto se distinguen los gastos de poblamiento del resto de las erogaciones. Los primeros, al ayudar a consolidar la ocupación del lugar incentivando la expansión territorial y el aumento demográfico, contribuían al crecimiento económico del área. Los segundos, en cambio, se limitaban a dinamizar la economía 
aumentando la actividad económica de esos años debido a su influencia sobre la demanda de bienes y servicios. Justamente por esto es necesario indagar con detenimiento en los asientos contenidos en los libros de las cajas para poder determinar la distribución y naturaleza de los gastos. De todas maneras el caso de Maldonado parece ser bastante peculiar en el contexto de la monarquía española ya que en la mayoría de las cajas predominaban otros tipos de gastos, especialmente los salarios.

Por otro lado, el estudio del gasto fiscal, especialmente en lugares estratégicos desde el punto de vista de la defensa de los dominios americanos de la monarquía borbónica, como es el caso de Maldonado, puede brindar un campo fértil para examinar la importancia de la dimensión fiscal y militar dentro de la estructura burocrática de la corona.

En este sentido los debates en torno a la caracterización de la monarquía como un Estado fiscal-militar necesitan incorporar al análisis la fiscalidad y la defensa militar de los dominios americanos. El traslado de recursos fiscales de los centros mineros a los puertos para sostener el gasto militar era un recurso que se replicaba en el Caribe, en el Pacífico y en el Río de la Plata y muestra que es necesario estudiar las erogaciones que requería ese sistema defensivo y no sólo las remesas de caudales hacia la península. Conservar su territorio en América implicaba para la corona un esfuerzo fiscal significativo que podría ser comparado con el que se realizaba para sostener las guerras emprendidas en el viejo continente.

La dimensión fiscal-militar permite comprender una parte esencial del aparato burocrático. Es un espacio donde las reformas borbónicas tuvieron un impacto profundo, especialmente desde el punto de vista de la centralización y la profesionalización de los funcionarios. Sin embargo, no hay que olvidar que una parte importante de la defensa militar dependía de la movilización de las milicias compuestas de vecinos, tal como vimos a través de los pagos de sueldos militares. Es decir, el análisis de la fiscalidad vinculada a los gastos militares solamente brinda información sobre las características de uno de los actores del sistema político: la corona. La identificación de los intereses de ese actor puede ayudar a estudiar las negociaciones entre los distintos poderes que conformaban el sistema político, ya sea que lo denominemos monarquía compuesta o policéntrica. ${ }^{31} \mathrm{De}$ esta manera la conjunción de estudios sobre el desempeño fiscal de la Real Hacienda española en América y Europa durante el siglo XVIII estimula un debate que en última instancia contribuye a enriquecer los análisis sobre

${ }^{31}$ Para un análisis de la monarquía española como una monarquía compuesta, véase Russell y Gallego (1996), y para una caracterización como una monarquía policéntrica, véase Cardim, Herzog, Ruiz y Gaetano (2012). 
la naturaleza del sistema político de la monarquía, las consecuencias de las reformas borbónicas y la crisis de los últimos años del periodo.

\section{LISTA DE REFERENCIAS}

Amaral, S. (mayo, 1984). Public expenditure financing in the colonial treasury: An analysis of the Real Caja de Buenos Aires accounts, 1789-1791. Hispanic American Historical Review, 64(2), 287-295. DOI: 10.2307/2514518

AmARAL, S. (2011). Las finanzas arcaicas: la atención del déficit fiscal en la Real Caja de Buenos Aires, 1789-1811. Investigaciones y Ensayos, 60, 381-436.

Apolant, J. A. (1970). Operativo Patagonia: Historia de la mayor aportación demográfica masiva a la Banda Oriental con la nómina completa, filiaciones y destino de las familias pobladoras. Montevideo: Letras.

BARbier, J. y Klein, H. (1985). Las prioridades de un monarca ilustrado: el gasto público bajo el reinado de Carlos III. Revista de Historia Económica, 3(3). Recuperado de http://orff.uc3m.es/bitstream/handle/10016/1638/RHE-1985-III-1-Barbier. Herbert.Klein.pdf?sequence $=1$

Biangardi, N. (2013a). Una nueva área para la región. Poblamiento y crecimiento económico en Maldonado (1755-1814). Revista Uruguaya de Historia Económica, 3(4). Recuperado de http://www.audhe.org.uy/images/stories/upload/Revista/Revista_4/biangardi $\% 2011 \% 20 \mathrm{a} \% 2030$.pdf

Biangardi, N. (2013b). Poblamiento; crecimiento económico y poderes locales en un área de la región Río de la Plata: Maldonado 1755-1814 (Tesis inédita de maestría). Universidad Nacional de Tres de Febrero, Argentina.

Cardim, P., Herzog, T., Ruiz, J. J. y Sabatini, G. (eds.) (2012). Polycentric monarchies: How early modern Spain and Portugal achieve and maintain a global hegemony? Brighton: Sussex Academic Press.

Cuesta, M. (2009). Impuestos imperiales: la Caja Real de Buenos Aires (1700-1800). Temas de Historia Argentina y Americana, 14, Recuperado de http://bibliotecadigital. uca.edu.ar/repositorio/revistas/impuestos-imperiales-caja-real-buenos-aires.pdf

DíAz De Guerra, M. A. (1988). Historia de Maldonado (2 vols.). Maldonado: Intendencia de Maldonado.

DJEnderedjian, J. (2008). Roots of revolution: Frontier settlement policy and the emergence of new spaces of power in the Río de la Plata borderlands 1777-1810. Hispanic American Historical Review, 88(4), 639-668. DOI: 10.1215/00182168-2008-003

Fajardo, F. (1958). Historia de la ciudad de Minas. Boletín Histórico del Ejército, 7576. Recuperado de http://www.artigas.org.uy/bibliotecas/he/066.\%20Boletin $\% 20$ Historico. $\% 20$ Nos. $\% 2075 \% 20-\% 2076 /$ Publicacion.pdf

Fajardo, F. (1967). Artigas, Azara y Pérez del Puerto. Boletín Histórico del Ejército, 112-115. Recuperado de http://www.artigas.org.uy/bibliotecas/he/078.\%20Boletin $\% 20$ Historico. $\% 20$ Nos. $\% 20112 \% 20-\% 20115 /$ Publicacion.pdf 
Fajardo, F. (1977). Sembrador de pueblos. Boletín Histórico del Ejército, 247-250. Recuperado de http://www.artigas.org.uy/bibliotecas/he/114.\%20Boletin\%20Historico. $\% 20$ Nos. $\% 20247 \% 20-\% 20250 /$ Publicacion.pdf

Fajardo, F. (1978). Ministro de la Real Hacienda. Boletín Histórico del Ejército, 259-272. Recuperado de http://www.artigas.org.uy

Flores, R. F. (2012). Los situados peruanos: desde Chile hasta Panamá (1700-1800). En C. Marichal y J. von Grafenstein, El secreto del imperio español: los situados coloniales en el siglo XVIII. México: El Colegio de México/Instituto de Investigaciones Dr. José María Luis Mora.

Fradkin, R. (2015). Las milicias de caballería de Buenos Aires, 1752-1805. Fronteras de la Historia, 19(1), 124-150.

Garavaglia, J. C. y Grosso, J. C. (1987). Las alcabalas novohispanas (1776-1821). México: Archivo General de la Nación.

HALPERín, T. (1982). Guerra y finanzas en los orígenes del Estado argentino (1791-1850). Buenos Aires: Editorial de Belgrano.

Jumar, F. (2012). La región Río de la Plata y su complejo portuario durante el Antiguo Régimen. En R. Fradkin (dir.), Historia de la provincia de Buenos Aires, t. 2: De la conquista a la crisis de 1820. Buenos Aires: Edhasa.

Jumar, F. y SANDrín, M. E. (29 y 30 de octubre, 2013). La estructura del gasto de la Real Hacienda en Buenos Aires, 1734-1742: la corona y la economía local. Coloquio internacional El Gasto Fiscal en los Imperios Ibéricos (siglo XVIII), Instituto de Investigaciones Dr. José María Luis Mora, México.

Jumar, F. y Biangardi, N. (2014). Espacio económico y territorialidad en el Río de la Plata del siglo XVIII. En R. Richard-Jorba y M. Bonaudo (coords.). Historia regional: enfoques y articulaciones para complejizar una historia nacional. La Plata: Universidad de La Plata

KLEIN, H. (agosto, 1973). Structure and profitability of royal finance in the viceroyalty of the Río de la Plata in 1790. Hispanic American Historical Review, 53(3), 440-469. DOI: $10.2307 / 2512973$

Klein, H. (1999). Las finanzas reales. En Academia Nacional de la Historia, Nueva historia de la nación argentina (t. III). Buenos Aires: Autor/Planeta.

Marichal, C. y Souto, M. (2012). La Nueva España y la financiación del imperio español en América: los situados para el Caribe en el siglo XVIII. En C. MARICHAL y J. VON GRAFENSTEIn, El secreto del imperio español: los situados coloniales en el siglo XVIII. México: El Colegio de México/Instituto de Investigaciones Dr. José María Luis Mora.

Meisel, A. (2000). Subsidy-led growth in a fortified port: Cartagena de Indias and the Situado, 1751-1815. Borradores de Economía, 167. Recuperado de http://www.banrep.gov.co/sites/default/files/publicaciones/archivos/borra167.pdf

MuÑoz, E. A. (2010). Estructura del gasto del ingreso en la Caja Real de Santafé, 18031815. Anuario Colombiano de Historia Social y de la Cultura, 37(2). Recuperado de http://www.revistas.unal.edu.co/index.php/achsc/article/view/19183/20127 
Russell, C. y Gallego, J. A. (dirs.) (1996). Las monarquías del antiguo régimen, imonarquías compuestas? Madrid: Editorial Complutense.

SÁnCHEZ, E. (2013). Corte de Caja. La Real Hacienda de Nueva España y el primer reformismo fiscal de los Borbones (1720-1755). Alcances y contradicciones. México: Instituto de Investigaciones Dr. José María Luis Mora.

SANTILLI, D. (2013). ¿Perjudiciales o beneficiosas? La discusión sobre el impacto económico de las reformas borbónicas en Buenos Aires y su entorno. Fronteras de la Historia, 18(2). Recuperado de http://kt.micrositios.net/action.php?kt_path_ info=ktcore.actions.document.view\&fDocumentId=17046\&forceopen

Torres-SÁnchez, R. (2007). Possibilities and limits: Testing the fiscal-military state in the Anglo-Spanish war of 1779-1783. En R. Torres-SÁnchez (ed.), War, State and development: Fiscal military states in the eighteenth century. Navarra: Ediciones Universidad de Navarra.

Torres-SÁnchez, R. (2013). El precio de la guerra. El Estado-fiscal-militar de Carlos III (1779-1783). Madrid: Marcial Pons. 